\title{
Hyaline corneal opacities in a case of Rieger's anomaly
}

\author{
T. H. KIRKHAM \\ Sheffield Royal Infirmary
}

Rieger's anomaly is characterized by a prominent border ring of Schwalbe into which is inserted coarse strands of mesodermal tissue derived from the anterior mesodermal leaf of the iris. Corneal opacities of various types associated with Rieger's anomaly have previously ${ }_{i j}^{\omega}$ been reported (Theodore, I944; Dark and Kirkham, 1968). The presence of hyalinew ridges on the posterior corneal surface (other than the prominent border ring of Schwalbe) in Rieger's anomaly has not been previously documented.

\section{Case report}

An 8-year-old girl was referred from the school clinic because of left esotropia. She was the sixth child of a healthy mother. Both pregnancy and birth had been normal. The family was investigated but no cases of Rieger's anomaly were found.

\section{Examination}

The child had no general physical abnormalities. Antimongoloid obliquity of the palpebral apertures was present. Three well-defined rows of lashes in the upper lids resulted in the appearanceO of an unusually luxuriant growth of the lashes. Left esotropia of $20 \triangle$ was present.

RIGHTEYE The visual acuity was 6/6. Megalocornea was present, the corneal diameters being. I $3 \times 13 \mathrm{~mm}$. A prominent ring of Schwalbe was visible throughout $360^{\circ}$ into which were inserted응. strands of mesodermal tissue from the hypoplastic anterior layer of the iris. Prominent parallelo hyaline ridges in the form of a letter $T$ were present on Descemet's membrane unassociated with iris 3 . mesodermal adhesions. The ridges projected slightly posteriorly into the anterior chamber. Theô fundus was normal. Applanation ocular tension was $18 \mathrm{~mm}$. $\mathrm{Hg}$.

LEFTEYE The visual acuity was $6 / 18$. The corneal diameters were $13 \times 13 \mathrm{~mm}$. and, as in the right eye, mesodermal strands were inserted into a prominent ring of Schwalbe. Parallel hyalineo ridges were present on Descemet's membrane in an oval pattern over the nasal half of the cornea. N Diffuse opacification of Descemet's membrane was present over the temporal half of the cornea Both the ridges and the diffuse opacity were unassociated with mesodermal adhesions. The fundus was normal. The applanation ocular tension was $16 \mathrm{~mm}$. $\mathrm{Hg}$.

\section{Discussion}

Apart from the prominent ring of Schwalbe, hyaline ridges on the posterior corneal surface have not been previously described in cases of Rieger's anomaly. Such hyaline ridges areo usually associated with birth trauma or buphthalmos. Hyaline opacities secondary to $\mathbb{\mathbb { D }}$ birth trauma are usually linear and vertically disposed. The absence of corneal astigmat $-\overrightarrow{\mathbb{D}}$ ism and of a history of birth trauma renders trauma an unlikely explanation for the appear 
ances in this case. The opacities could be explained on the basis of a defect in the cleavage of the anterior chamber during its development. The absence of lens opacities and of localized defects related to the ridges in the underlying iris stroma argue against this possibility. Furthermore, the curvatures of the anterior and posterior corneal surfaces were within normal limits.

Finally, it is possible to speculate that there has been a period of raised ocular tension at some stage during development which could explain the presence of the hyaline ridges and the opacities in Descemet's membrane as well as the megalocornea. This would appear to be the most likely explanation. However, applanation ocular tensions measured over a period of 12 months have always been within normal limits. Moreover, the oval disposition of the ridges in the left eye does not conform to the usual pattern of opacification seen in cong enital glaucoma.

Antimongoloid obliquity of the palpebral apertures has previously been noted in Rieger's anomaly (Lemmingson, I96r). This abnormality is often associated with general maldevelopment of the face, and several craniofacial anomalies in conjunction with Rieger's anomaly have been described (Lemmingson, I96r ; Collier, r962).

\section{Summary}

A case of Rieger's anomaly associated with linear hyaline opacities in Descemet's membrane is described. It is believed that this represents a new observation in association with Rieger's anomaly. Possible explanations for the presence of the hyaline opacities are discussed.

I am indebted to Mr. Alan Stanworth for allowing me to report on his patient.

\section{References}

Collier, m. (1962) Ann. Oculist. (Paris), 195, $5^{12}$

DARK, A. J., and KIRKHAM, T. H. (1968) Brit. F. Ophthal., 52, 631

Lemmingson, w. (196i) Klin. Mbl. Augenheilk., 138, 96

THEODORE, F. H. (1944) Arch. Ophthal. (Chicago), 31, 138 